\title{
RESPONSABILIDADE CIVIL DO MÉDICO: PERSPECTIVAS À LUZ DA TEORIA DA PERDA DE UMA CHANCE
}

\section{Otávio Augusto Milani Nunes; ${ }^{1}$ Catiane Medianeira Milani²; João Pedro Seefeldt Pessoa $^{3}$}

\section{RESUMO}

Considerando a evolução do entendimento acerca de responsabilidade civil no ordenamento jurídico pátrio, especialmente quanto à aplicabilidade do moderno instituto da Perda de Uma Chance, o presente artigo busca analisar a viabilidade da sua aplicação como modalidade autônoma de reparação na seara médica. Nos moldes do entendimento delineado pelo Superior Tribunal de Justiça até os dias atuais, busca-se avaliar em que medida é possível responsabilizar civilmente o médico, por sua conduta culposa, pela subtração da chance de cura ou de uma maior ou melhor sobrevida. Considerando que o dano em apreço resulta, em primeiro plano, da doença, fato inerente à vida e evidentemente fora do domínio do profissional, discute-se: há possibilidade de responsabilização civil do médico com fundamento na perda de uma chance? Objetivando elucidar tal questionamento, utiliza-se o método de abordagem dialético e propõe-se, enquanto não sobrevier uma solução normativa, uma interpretação equânime na aplicação deste instituto.

Palavras-chave: Culpa; Direito Médico; Indenização.

Eixo Temático: Direitos, Políticas Públicas e Diversidade - DPD.

\section{INTRODUÇÃO}

A evolução da sociedade e os conflitos que surgem dos novos formatos das relações envolvendo os atores sociais impõe a constante releitura dos institutos jurídicos a fim de assegurar a harmonização do convivío social.

A responsabilidade civil, que em sua concepção clássica tinha por essência sancionar o ofensor, com nítido viés punitivista, não se mostra mais suficiente para

\footnotetext{
1 Autor. Acadêmico de Direito na Universidade Federal de Santa Maria; E-mail: otavioamnunes@gmail.com

2 Autora: Procuradora Federal, Pós-graduanda em Advocacia Pública na Escola da Advocacia-Geral da União; E-mail: catianemilani@gmail.com

${ }^{3}$ Orientador. Professor no Departamento de Direito da Universidade Federal de Santa Maria. Mestre em Direito pela Universidad de León (ULE) e Mestre em Direito pela Universidade Federal de Santa Maria - UFSM E-mail: joao.seefeldt@ufsm.br
} 
reger os conflitos sociais. O dano, que era exclusivamente patrimonial, assume novos contornos com a admissão, hoje não mais controversa, da possibilidade de indenização por dano exclusivamente moral, desvinculada da esfera material e, mais recentemente, do dano estético e existencial, atualmente admitidos no ordenamento jurídico brasileiro. A existência de culpa, filtro imprescindível para responsabilização civil sob a ótica punitivista, deixou der ser necessária para a responsabilização do ofensor, passando a doutrina, a jurisprudência e também o legislador, inclusive o constitucional, a admitir a possibilidade de responsabilização objetiva, independentemtne de prova da culpa pelo evento danoso.

Nesse novo cenário, passa-se a percceber a responsabilidade civil a partir de uma visão holística permeada pela solidariedade e colaboração entre os atores sociais, com aptidão para gerar outras eficácias, desenvolvendo-se a partir dessa percpção, por exemplo, a possibilidade de responsabilização do agente que, com sua conduta, faz desaparecer a probalidade de um benefício futuro para outro indíviduo, ou seja, o autor do fato, com seu comportamento, priva a vítima da chance de uma vantagem, idéia embrionária que dará origem a teoria da perda de uma chance.

Atualmente aceita pela doutrina e jurisprudência brasileira para reparar situações fáticas diversas, a teoria da chance perdida ainda carece de previsão normativa, compreendendo, para o direito, em síntese, a probabilidade de obter uma vantagem ou evitar uma perda.

O presente trabalho busca refletir sobre a teoria da perda de uma chance e a viabilidade de sua incidência, como forma autonoma de reparação civil no âmbito das relações envolvendo médico-paciente, buscando-se responder ao seguinte questionamento: é possível responsabilizar civilmente o médico, por sua conduta culposa, pela subtração da chance de cura ou de uma maior ou melhor sobrevida, à luz da Teoria da Perda de Uma Chance? Nesse sentido, problematiza-se a (im)possibilidade de responsabilização civil do profissional médico, pela perda de uma chance do paciente, a partir da premissa de que o dano resulta, em primeiro plano, da doença e suas consequencias, fato inerente à vida e evidentemente fora do domínio do profissional.

Após breves considerações históricas sobre a evolução da responsabildiade 
civil, com utilização do método de abordagem dialético, investiga-se a possibilidade de responsabilização civil do médico pela chance perdida pelo paciente, para propor, ao final, após reflexão sobre julgados paradigmáticos do Superior Tribunal de Justiça, uma interpretação equânime e minimamente parametrizada na aplicação da teoria da perda de uma chance no sistema jurídico brasileiro.

\section{BREVES CONSIDERAÇÕES SOBRE A EVOLUÇÃO DA RESPONSABILDIDADE CIVIL - DA CULPA À PERDA DE UMA CHANCE}

Historicamente, a responsabilidade civil foi norteada pelo pensamento dominante de sua época. Enquanto o liberalismo foi o regime vigente, onde vigorava a individualidade, a responsabilidade civil era subjetiva, apenas. Dessa forma, não se permitia, em consonância com os preceitos morais então prevalentes, que houvesse responsabilização sem a comprovação da culpa. Tratava-se, portanto, de um modelo com viés mais punitivista e menos reparador.

Com o desdobrar da revolução industrial, seus reflexos levaram ao remodelamento das relações sociais e, por conseguinte, dos institutos jurídicos, impactando também no viés da responsabilidade civil (AFONSO NETO, 2009). Isso, porque a teoria subjetiva não mais atende à demanda oriunda das transformações sociais, especialmente considerando a pesada carga da prova da culpa sobre a vítima.

É nesse contexto que surge o conceito de responsabilidade objetiva, dispensando-se a prova culpa do agente, que passa a ser presumida em algumas situações, de modo que "todo dano é indenizável, e deve ser reparado por quem a ele se liga por um nexo de causalidade, independentemente de culpa" (GONÇALVES, 2012, p. 49). Contudo, permanece sendo necessário a prova de uma conduta comissiva ou omissiva - e de um dano interligados por um nexo de causalidade.

A partir dessa proposição, focada na reparação da vítima - e não mais apenas na punição do agente - abriu-se espaço para percepção de outros danos indenizáveis, porquanto se vislumbrou a necessidade de solidariedade e cooperação no campo da responsabilidade civil. Afinal, não mais percebia-se justo que a vítima suportasse os prejuízos quando a teorização clássica não respondesse aos seus problemas.

Nesse sentido, José Jairo Gomes alerta que, ao interpretar globalmente o evento, tendo como prisma a solidariedade e a colaboração, o intérprete não deve 
EDUCAÇÃO, SAÚDE

ETECNOLOGIA

26 A 28 DE OUTUBRO DE 2021

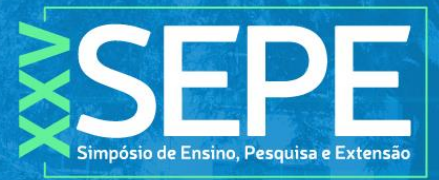

QUFN

considerar em primeiro plano apenas os aspectos econômico patrimonais que decorrem do evento, argumentando que "o enfoque primeiro a ser considerado deve dizer respeito à necessidade de se tornarem mais humanos e solidários os comportamentos individuais e coletivos no ambiente social [...]" (ROSENVALD, 2017, p. 45).

Para além disso, há diversas situações na vida cotidiana em que, diante de um ato ofensivo de um sujeito, alguém se vê privado da oportunidade de obter uma determinada vantagem ou evitar um prejuízo. É a partir dessa percepção que surge na França, na década de 60, a teoria da perda de uma chance, essencialmente fundamentada na probabilidade de que em determinada situação fática é possível prospectar que haveria um ganho e na certeza de que, da vantagem perdida, resultou um prejuízo, o qual dá embasa a responsabilidade do ofensor. Em síntese, há uma chance perdida quando, em virtude do comportamente de alguém, desaparece para outrem a probalidade de obter um benefício ou de evitar uma perda.

Nesse contexto, à luz da teoria da perda de uma chance, para que seja possível caracterizar a responsabilidade civil, basta que haja uma conduta que vá de encontro a uma obrigação jurídica, desde que tal conduta seja voluntária, lícita ou ilícita e que traga dano a outra pessoa (GONÇALVES, 2014).

Desde o julgado inaugural que entendeu viável a incidência da referida teoria no direito brasileiro, datado do ano de 2005, no caso conhecido como "show do milhão" (REsp 788.459/BA, Rel. Ministro FERNANDO GONÇALVES, QUARTA TURMA, julgado em 08/11/2005, DJ 13/03/2006) (BRASIL, 2006, p. 334), constata-se uma crescente ampliação da aplicação dessa teoria nas mais diversas áreas do direito, tanto na esfera das relações privadas stricto sensu quanto na responsabilidade civil do Estado.

\section{A RESPONSABILIDADE CIVIL DO MÉDICO A PARTIR DA TEORIA DA PERDA DE UMA CHANCE}

A teoria da perda de uma chance, conforme já referido, tem origem na constatação de que ações ou omissões de alguns podem vir a frustrar a chance de realização de objetivos ou até mesmo sonhos de outros. Com intuito tão somente de 
indenizar a chance perdida e não o objeto esperado, notadamente porque inviável dimensionar a extensão de eventual dano inocorrido, a doutrina e jurisprudência brasileiras, apesar da ausência uma base normativa sólida, sinalizam positivamente ao acolhimento da teoria da chance perdida pelo sistema jurídico brasileiro.

A teoria da perda de uma chance consiste na cessação, devido a um fato antijurídico, de um meio que possibilite a uma pessoa o cenário de vir a obter, no futuro, algo que seria benéfico, e que, devido a esse fato, essa oportunidade se tornou inviável. Ou seja, define-se como um comportamento ilícito - ação ou omissão - que acaba fazendo desaparecer a oportunidade da incidência de um acontecimento que poderia gerar uma vantagem futura para a vítima ou então obstaria o risco de ocorrer algum prejuízo a ela.

De acordo com essa teoria, o que se indeniza, frise-se, não é o resultado, pois não há certeza sobre sua ocorrência, mas sim a oportunidade perdida de se alcançar o resultado almejado ou o prejuízo que se quer evitar caso o ato omissivo ou comissivo não tivesse sido realizado. Em outras palavras, a reparação deve sobepesar a perda da possibilidade de alguém auferir alguma vantagem, e não dos ganhos efetivamente perdidos.

Assim, para que haja a indenização, além de comprovar a oportunidade perdida de alcançar o resultado esperado, é indispensável provar que a perda em questão é séria, real e certa, pois ao imputar o agente o papel de reparar o dano, deve-se demonstrar que o dano em questão causou mesmo um prejuízo à vítima e que se o mesmo não tivesse ocorrido a vítima teria chances sérias, reais e certas de alcançar o resultado esperado.

Em outras palavras, a perda de uma chance acontece "quando, em virtude da conduta de outrem, desaparece a probabilidade de um evento que possibilitaria um benefício futuro para a vítima, como progredir na carreira artística ou militar, arrumar um melhor emprego [...]" (CAVALIERI FILHO, 2009, p. 74). Essa teoria versa sobre a responsabilidade civil da reparação de um dano diferente daqueles previstos no art. 403, do Código Civil, sendo, pois, uma modalidade sui generis, já que "a expansão dos prejuízos reparáveis é um dos principais vetores de evolução da responsabilidade civil e é natural que mais e mais espécies de prejuízo sejam paulatinamente 
reconhecidas" (CARNAÚBA, 2013, p. 17).

Ainda, para Cavalieri Filho (2009, p. 75), a chance perdida "deverá caracterizar um prejuízo material ou imaterial resultante de fato consumado, não hipotético", de modo que ser "preciso verificar em cada caso se o resultado favorável seria razoável ou se não passaria de mera possibilidade aleatória". Vê-se também o pensamento de Savi (2006, p. 63) que estabelece "o fato de a situação ser idônea a produzir apenas provavelmente e não com absoluta certeza o lucro a esse ligado influi não sobre a existência, mas sobre a valoração do dano". Assim, a chance de lucro terá sempre um valor menor que a vitória futura, o que refletirá no montante da indenização.

A aplicação da referida teoria como modalidade autônoma de responsabilidade civil do médico é uma criação doutrinária e jurisprudencial, por meio do qual se analisa o dever de reparar um dano advindo de erro do profissional que impediu a obtenção de um resultado almejado - desde que estatisticamente provável, concreto e real.

No que tange especificamente ao erro do médico, por ocasião do julgamento do recurso especial $n$ ํ 1.662.338-PR, o STJ entendeu, com fundamento em decisões anteriores do tribunal, pela possibilidade de aplicação da teoria de uma chance como critério para apurar a responsabilidade civil quando o erro médico reduzir as possibilidades concretas de cura do paciente, afastando a incidência do instituto quando se tratar de chance remota ou improvável de cura (BRASIL, 2013).

No caso concreto que deu origem ao precedente referido no parágrafo anterior, os pais de uma jovem de 21 anos de idade, saudável, atleta e sem histórico de problemas neurológicos, pretendiam obter compensação por danos morais em razão do óbito de sua filha, argumentando ter o médico atuado com culpa (imperícia) no tratamento de urgência dispensado à jovem - alta hospitalar após antendimento em pronto socorro em vez de internação hospitalar- o que teria ocasionado o óbito (BRASIL, 2013).

A conclusão do Tribunal, tendo por base a prova pericial produzida nos autos que apontou ser improvável a ocorrência do resultado e ser adequada a conduta adotada pelo médico, foi no sentido de não ser possível concluir pela existência de erro crasso passível de caracterizar uma frustação de chance concreta, real, com alto grau de probabilidade (BRASIL, 2013). Por conseguinte, considerando ser remota ou 
impovável a chance, entendeu não haver base fática a ensejar a aplicação da teoria da perda de uma chance, afastando a caracterização de erro médico passível de responsabilização, destacando que o resultado - morte - foi um evento raro e extraordinário ligado à ciência médica (BRASIL, 2013).

\section{METODOLOGIA}

Em termos metodológicos, é utilizado o método de abordagem dialético, visando analisar qualitativamente o tema de pesquisa, desenvolvendo-se uma interrelação entre os assuntos abordados, utilizando-se especialmente o estudo de caso para demonstrar o cenário atual. Quanto ao procedimento, utiliza-se o método monográfico, com fim de extrair conclusões sobre o tema a partir da análise relacional de um precedente judicial. Em relação às técnicas de pesquisa, faz-se uso da documentação indireta, com pesquisa documental e bibliográfica.

\section{RESULTADOS E DISCUSSÕES}

A ausência de previsão normativa expressa dificulta a compreensão e fixação de diretrizes mínimas hábeis a conferir ao instituto segurança jurídica e evitar o casuísmo. Inobstante, não há como afastar a incidência da teoria dos casos concretos que são submetidos ao julgamento do Poder Judiciário, que cresceram consideravelmente nesses 15 anos posteriores ao emblemático julgamento envolvendo o caso conhecido como "show do milhão".

$\mathrm{Na}$ seara médica, entende-se pela responsabilização do profissional médico quando, por agir de forma equivocada e contrária às normas gerais da medicina, este impede que o paciente obtenha a cura de determinada doença ou ao menos alcance sobrevida com qualidade que seria esperada. A perda de uma chance, ao ser aplicada à atividade médica, ficou estabelecida como sendo teoria da perda de uma chance de cura ou de sobrevivência (CAVALIEIRI FILHO, 2014).

É mister salientar que o dano não decorre diretamente do desfecho suportado pelo paciente, mas sim da real possibilidade perdida por este de experimentar uma vivência menos dramática, ou seja, o médico não causa a moléstia nem o resultado, mas por um erro de sua conduta, a existência do paciente é diretamente afetada. 
Conforme explanado acima, para a ocorrência da responsabilidade civil é necessário que coexistam ato ilícito, nexo causal e dano. No contexto em tela, o ato ilícito decorrerá do erro de procedimento, que pode ser entendido como todo ato médico, que compreende o conjunto das atividades de diagnóstico, tratamento, encaminhamento de um paciente e prevenção de agravos.

Ainda, salienta-se que ao definir como excludentes o estado de necessidade, legítima defesa, exercício regular de direito e estrito cumprimento do dever legal, caso fortuito ou força maior, culpa exclusiva da vítima e fato de terceiro. A chamada "cláusula de não indenizar" também é um instituto que exclui, quando prevista em contrato, a responsabilidade em indenizar.

Por outro lado, alguns doutrinadores manifestam-se no sentido de afastar a aplicação da teoria da perda de uma chance na seara médica por entender ou que o dano não decorre do ato médico ou que não é possível a responsabilização por se tratar de um cenário hipotético e incerto. Entretanto, tal concepção diverge da doutrina majoritária que considera o dano analisado justamente a perda de uma chance e não o resultado ao qual o paciente será vitimado.

Nesse sentido, Nancy Andrighi, Ministra do Superior Tribunal de Justiça, destaca ser :

[...] forçoso distinguir que o dano não se refere ao agravamento da doença ou o óbito, mas sim à chance perdida de uma possibilidade de cura ou sobrevida mais digna. Assim, a perda de uma chance de sobrevivência ou de cura 'consubstancia uma modalidade autônoma de indenização, passível de ser invocada nas hipóteses em que não se puder apurar a responsabilidade direta do agente pelo dano final. Nessas situações, o agente não responde pelo resultado para o qual sua conduta pode ter contribuído, mas apenas pela chance de que ele privou à paciente. Com isso, resolve-se, de maneira eficiente, toda a perplexidade que a apuração do nexo causal pode suscitar" (RESp 1254141/PR, 3ㄹ Turma, DJe de 20/02/2013) (BRASIL, 2013)

A teoria da chance perdida vem sendo acolhida pela doutrina e jurisprudência brasileira, inclusive pelo Superior Tribunal de Justiça (STJ), que em precedente paradigmático entendeu ser necessário, além da conduta e do nexo causal, que a chance perdida seja real, atual e certa, acompanhada de um juízo de probabilidade de se obter um benefício ou evitar um prejuízo, não podendo se tratar de mera possibilidade, já que a expectativa abstrata, na dimensão da responsabilidade civil, não é indenizável. 


\section{CONCLUSÃO}

A perda de uma chance trata-se de teoria do direito estrangeiro, que apesar da ausência de previsão normativa expressa, vem sendo internalizada pela doutrina e pela jurisprudência brasiliera. Por envolver tema relativamente novo no Brasil, há muito debate e pouco consenso sobre o tema, o que evidencia a urgência na adoção de diretrizes mínimas, ainda que não normatizadas, para que seja evitado o desvirtuamento, adaptações errôneas ou até mesmo que o instituto seja utilizado para uma busca desenfreada de indenizações para qualquer situação fática, caindo na chamada "indústria do dano moral".

No caso de aplicação da teoria da perda de uma chance, a reparação não irá corresponder, frise-se, à vantagem esperada ou aos resultados pretendidos, devendo ser quantificada com base na chance perdida. Nesse sentido, além da normatização mínima sobre o tema, urge a necessidade de harmonização doutrinária e jurisprudencial envolvendo o instituto a fim de evitar o casuísmo e o ativismo, tão prejudiciais à segurança jurídica, notadamente diante da possibilidade de desfechos opostos em situações semelhantes, em especial diante da complexidade e inerdisciplinaridade do instituto.

\section{REFERÊNCIAS}

AFONSO NETO, José. A responsabilidade civil: a teoria da perda de uma chance. In: Revista do Centro Acadêmico Afonso Pena - CAAP, Belo Horizonte, v. 15, n. 1, p. 345-362, jan. 2009. Disponível

em: https://revistadocaap.direito.ufmg.br/index.php/revista/article/view/33. Acesso em: 23 set. 2021.

BRASIL. Superior Tribunal de Justiça. Recurso Especial no 788.549/BA. Recorrente: BF Utilidades Domésticas LTDA. Recorrido: Ana Lúcia Serbeto de Freitas Matos. Relator: Min. Hélio Quaglia Barbosa. Brasília, DF, 08 de novembro de 2005. Diário de Justiça Eletrônico. Brasília, 13 mar. 2006. Disponível em: 
https://processo.stj.jus.br/processo/revista/documento/mediado/?componente=ITA\&s equencial $=592103 \&$ num registro $=200501724109 \&$ data $=20060313 \&$ peticao numero =-1\&formato=PDF. Acesso em: 23 set. 2021.

BRASIL. Superior Tribunal de Justiça. Recurso Especial nำ 1.254.141/PR. Recorrente: João Batista Neiva. Recorrido: Vilma de Lima Oliveira - Espólio e Outros. Relator: Min. Nancy Andrighi. Brasília, DF, 04 de dezembro de 2012. Diário de Justiça Eletrônico. Brasília, 20 fev. 2013.2 Disponível em: https://processo.stj.jus.br/processo/revista/documento/mediado/?componente=ITA\&s equencial=1199921\&num registro=201100789394\&data=20130220\&peticao numer

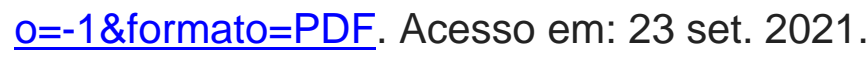

BRASIL. Superior Tribunal de Justiça. Recurso Especial no 1.662.338/SP. Recorrente: Geraldo Alves Ferreira Filho, Maria Silva Waldemarin Ferreira e Márcio Antonio Arantes. Recorrido: Os Mesmos. Relatora: Min. Nancy Andrighi. Brasília, DF, 12 de dezembro de 2017. Diário de Justiça Eletrônico. Brasília, 02 fev. 2018. Disponível em:

https://processo.stj.jus.br/processo/revista/documento/mediado/?componente=ITA\&s equencial $=1654017$ \&um registro $=201503075580$ \&data $=20180202 \&$ formato=PDF Acesso em: 23 set. 2021.

CARNAÚBA, Daniel Amaral. Responsabilidade civil pela perda de uma chance: a álea e a técnica. São Paulo: Método, 2013.

CAVALIERI FILHO, Sérgio. Programa de Responsabilidade Civil. 7. ed. rev. e ampl. São Paulo: Atlas, 2007.

FARIAS, Priscila Almeida. Aplicabilidade da teoria da perda de uma chance nos casos de erro médico. 2015. 55f. Monografia (Graduação) - Curso de Direito, Universidade Federal do Ceará, Faculdade de Direito, Curso de Direito, $\quad 2015 . \quad$ Dortaleza, em: 
http://repositorio.ufc.br/bitstream/riufc/25757/1/2015 tcc pafarias.pdf. Acesso em: 23 set. 2021.

GOMES, José Jairo. Responsabilidade civil e eticidade. Belo Horizonte: Del Rey, 2005.

GONÇALVES, Carlos Roberto. Curso de Responsabilidade Civil. 15 ed. São Paulo: Saraiva, 2014.

GONÇALVES, Carlos Roberto. Direito civil brasileiro: responsabilidade civil. 7. ed. São Paulo: Saraiva, 2012.

GONDIM, Glenda Gonçalves. A reparação civil na teoria da perda de uma chance. Dissertação (Mestrado) - Universidade Federal do Paraná - UFPR, Programa de PósGraduação em Direito, Curitiba, 2010. Disponível em: http://www.dominiopublico.gov.br/download/teste/arqs/cp146052.pdf. Acesso em: 23 set. 2021.

PETZOLDT, Ana Paula. A teoria da perda de uma chance de cura ou de sobrevivência por erro médico: análise do recurso especial 1243.141PR. 2017. 81f. Monografia (Graduação) - Curso de Direito, Universidade do Extremo Sul Catarinense - UNESC, Criciúma, $2017 . \quad$ Disponível em: http://repositorio.unesc.net/bitstream/1/5533/1/ANA\%20PAULA\%20PETZOLDT.pdf. Acesso em: 23 set. 2021.

RAMOS, Mariana Rezende. A teoria da perda de uma chance e o tratamento do Superior Tribunal de Justiça nos últimos 13 anos. 2019. 48f. Monografia (Graduação) - Curso de Direito, Universidade Evangélica de Goiás - UniEvangélica, Anápolis, 2019.

Disponível em:

http://repositorio.aee.edu.br/bitstream/aee/1300/1/Monografia\%20\%20Mariana\%20Rezende\%20Ramos.pdf Acesso em 23 set 2021. 
EDUCAÇÃO, SAÚDE

ETECNOLOGIA

26 A 28 DE OUTUBRO DE 2021

\section{QUFN}

ROSENVALD, N.; FARIAS, C. C. de; NETTO, F. P. B. Curso de Direito Civil: Responsabilidade Civil. 2.ed. São Paulo: Atlas, 2015.

SAVI, Sérgio. Responsabilidade civil por perda de uma chance. São Paulo: Atlas, 2007. 